C.A. РЕБРОВА ${ }^{1}$, Г.P. СЕРГEEBA ${ }^{2}$, К.М.Н.

${ }_{1}^{1}$ Санкт-Петербургский научно-исследовательский институт уха, горла, носа и речи Минздрава России

2 Северо-Западный государственный медицинский университет им. И.И. Мечникова Минздрава России, Санкт-Петербург

\title{
АЛЛЕРГИЧЕСКИЙ РИНИТ:
} ЛИЧНЫЙ КЛИНИЧЕСКИЙ ОПЫТ

\begin{abstract}
Аллергический ринит (AP) представляет серьезную медико-социальную проблему, обусловленную ростом заболеваемости аллергическим ринитом, несвоевременной диагностикой, частыми осложнениями, высокими экономическими затратами в области здравоохранения и снижением качества жизни и трудоспособности пациентов. Несмотря на известность данного заболевания, часто врачи недостаточно полно осведомлены о лечении, в связи с чем контроль над заболеванием не всегда может быть достигнут.
\end{abstract}

Ключевые слова: аллергический ринит, интраназальные кортикостероиды, длительность терапии.

\section{S.A. REBROVA ${ }^{1}$, G.R.SERGEEVA ${ }^{2}$, PhD in Medicine}

${ }^{1}$ Saint-Petersburg Research Institute of Ear, Throat, Nose and Speech. MH RF

${ }^{2}$ North-western State Medical University named after I.I.Mechnikov, MH RF

ALLERGIC RHINITIS: PERSONAL CLINICAL EXPERIENCE

Allergic rhinitis (AR) - this is a serious medical and social problems associated with increasing incidence of allergic rhinitis, delayed diagnosis of AR, frequent complications, high economic health costs, reduced quality of life and disability of patients. Despite the popularity of this disease, doctors often are not fully aware of the treatment, so it is often not achieved disease control

Keywords: allergic rhinitis, intranasal corticosteroids, the duration of therapy.

A ллергический ринит (AP) - это IgЕ-опосредованное воспаление слизистой оболочки полости носа, вызванное значимыми аллергенами и клинически проявляющееся ежедневными двумя и более симптомами: ринореей, чиханием, затруднением носового дыхания, зудом в полости носа. Симптомы обратимы спонтанно или под влиянием терапии [1].

AP является широко распространенным заболеванием, примерно до 40\% населения мира страдает аллергическим ринитом [1]. Заболеваемость АР в России составляет 12,7-24\%. Пик заболеваемости зарегистрирован в возрасте 18-24 лет [2], т. е. среди людей молодого и трудоспособного возраста.

AР существенно снижает качество жизни: 40\% пациентов страдают быстрой утомляемостью, 77\% имеют проблемы засыпания. У детей нарушается способность к обучению, нарушаются когнитивные функции. Около 93\% детей отмечают ухудшение результатов учебы. 75\% детей и подростков отмечают снижение концентрации внимания, 78\% испытывают трудности при выполнении школьных заданий [3-6].

АР имеет тесную связь с бронхиальной астмой (БА). Симптомы АР выявлены у 88\% пациентов с БА [2]. АР является независимым фактором развития БА, увеличивая шанс заболеть БА в три раза [7]. Исследование, проведенное в Великобритании, показало, что пациенты с БА в сочетании с АР имели неконтролируемое течение в 4-5 раз чаще, чем при наличии БА без ринита [8, 7]. В основе БА и АР лежит единое IgE-обусловленное аллергическое воспаление. В настоящее время считается, что ринит и астма являются проявлением единого заболевания объединенных дыхательных путей. Верхние и нижние дыхательные пути имеют как общие особенности строения: наличие реснитчатого эпителия, базальной мембраны, так и отличия: слизистая оболочка носа окружена сосудами, а слизистая оболочка бронхов окружена гладкой мускулатурой. Обструкция верхних дыхательных путей вызывается вазодилатацией и отеком, а обструкция нижних дыхательных путей вызвана констрикцией гладкой мускулатуры, отеком и гиперсекрецией [9-10]. Согласно рекомендациям ВОЗ пациентов с персистирующим аллергическим ринитом необходимо обследовать также и на предмет БА.

Многочисленными исследованиями было показано, что АР способствует возникновению заболеваний ЛОРорганов: синуситов, отитов, полипозных риносинуситов. У $24 \%$ детей АР является фактором, предрасполагающим к развитию острого и хронического отита, у 28\% - хронического синусита [2]. Минимальное воспаление слизистой оболочки носа имеется у больных АР, не имеющих клинических симптомов, что характеризуется постоянной экспрессией адгезивных молекул, которые являются рецепторами для риновирусов и способствуют снижению продукции гамма-интерферона, что приводит к частым ОРВИ у данной категории пациентов.

Остаются высокими экономические затраты на лечение АР. Стоимость лечения АР в Европе составляет примерно 2,5-3,5 млрд евро в год [1].

Наиболее часто причиной развития АР являются следующие аллергены:

- Пыльцевые аллергены. Пыльца - это мужские половые клетки растений, имеющие различную форму и величину. Для разных регионов нашей страны значимы разные виды пыльцы.

- Бытовые - аллергены клещей домашней пыли (наиболее частая причина аллергического ринита для СевероЗападного региона). 
Эпидермальные - аллергены животных (кошек, собак, грызунов, лошадей).

- Грибковые - споры плесневых и дрожжевых грибов. Количество спор грибов в окружающем воздухе зависит от времени года, зимой уменьшается, летом и осенью увеличивается.

- Профессиональные аллергены - представляют собой органические соединения растительного и животного происхождения, вещества микробного происхождения, органические и неорганические химические вещества, фармакологически активные вещества.

Согласно международным согласительным документам АР подразделяется [1]:

по характеру течения - на интермиттирующий (симптомы менее 4 дней в неделю и менее 4 недель в году) и персистирующий (симптомы более 4 дней в неделю и более 4 недель в году),

по тяжести - на легкое течение (клинические проявления не нарушают повседневной активности), среднетяжелое течение (симптомы нарушают повседневную активность, препятствуют работе), тяжелое течение (пациент не может нормально работать, проводить досуг).

В зависимости от преобладания симптомов АР можно выделить два варианта течения.

1. Экссудативный вариант, который проявляется частыми приступами чихания, водянистыми выделениями, зудом, непостоянной заложенностью носа, ухудшением носового дыхания в дневное время, часто сопутствующим конъюнктивитом.

2. Обструктивный вариант, который сопровождается незначительным чиханием, или чихание полностью отсутствует. Выделения - густые, зуд отсутствует, заложенность носа - сильно выражена, конъюнктивита нет, возможно ухудшение носового дыхания ночью.

Достаточно часто у пациентов с АР диагностируется полипоз, полисинусит, средний отит.

Синусит сопутствует аллергическому риниту в 70\% случаев. Раздражающее действие подтекающей слизи (постназальный затек) и хроническое воспаление в дыхательных путях провоцируют кашель, могут вызывать боли в животе.

Диагностика АР - это комплекс клинических и лабораторных методов исследования. До сих пор существует проблема недостаточной диагностики АР, несмотря на широкое освещение этой проблемы. В частности, проведен опрос 151 врача, проходивших обучение на цикле тематического усовершенствования «Методы диагностики и терапии аллергических заболеваний», с целью уточнения современного уровня знаний по ведению пациентов с атопическими заболеваниями. Доля постановки правильного диагноза на основании современных знаний составляет среди аллергологов 58\%, оториноларингологов - 83,3\%, среди педиатров правильно устанавливают диагноз 24,6\% врачей. Незнакомы с правильным алгоритмом назначения терапии 21,6\% терапевтов и 56,1\% педиатров. 33,3\% ЛОР-врачей и 25\% аллергологов также не знакомы с современными рекомендациями по лечению АР [11]. Часто от начала заболевания до момента постановки правильного диагноза проходят десятки лет, что приводит к несвоевременному лечению, и в результате эффективность терапии снижается, увеличивается ее объем, труднее достигается контроль над заболеванием. Очень часто обструктивная форма АР диагностируется ЛОР-врачами как вазомоторный ринит, что приводит к позднему обращению к аллергологу и, соответственно, к запоздалой диагностике. Следует отметить, что только врачаллерголог может достоверно диагностировать АР.

Основные принципы терапии AP:

- Предотвращение контакта с аллергенами и триггерами. Фармакотерапия, направленная на подавление аллергического воспаления.

- Аллерген-специфическая иммунотерапия (АСИТ).

- Обучение пациентов.

Элиминационная терапия проводится, если это возможно. Она высокоэффективна при пыльцевой и эпидермальной сенсибилизации.

Фармакотерапия: блокаторы Н-1-гистаминовых рецепторов, кромоны, антагонисты лейкотриеновых рецепторов, альфа-1-адреномиметики, антихолинергические препараты, интраназальные глюкокортикостероиды.

Блокаторы Н1-гистаминовых рецепторов используются более 80 лет. Разделение их на 1-е и 2-е поколение основано на способности в терапевтических дозах вызывать седативный эффект. Антигистаминные препараты (АГП) 1-го поколения имеют ограничения для использования из-за седативного эффекта и эффекта тахифилаксии. ARIA-2008, 2010 не рекомендует использование этих препаратов для лечения АР. АГП 2-го поколения и их метаболиты используются более 20 лет в клинической практике. Они высокоэффективны, при этом отсутствует тахифилаксия. Препараты используются внутрь или местно при легком течении АР или в сочетании с интраназальными кортикостероидами при более тяжелом течении АР.

Кромоны-стабилизаторы мембран тучных клеток. Существенный недостаток - это медленный эффект и синдром отмены.

Антагонисты лейкотриеновых рецепторов - в России это в основном таблетированные формы монтелукаста. Они менее эффективны, чем интраназальные кортикостероиды и АГП. Их рекомендовано использовать в лечении АР при его сочетании с БА.

Альфа-1-адреномиметики вызывают сокращение кавернозных тел нижних носовых раковин (альфа-2агонисты) или артериол слизистой оболочки полости носа (альфа-1-агонисты). Их использование оправданно при сопутствующей вирусной инфекции и в качестве симптоматической терапии на любой ступени лечения АР. Их рекомендуется применять не более 10 дней из-за риска развития медикаментозного ринита.

Антихолинергические препараты. В РФ представлены комбинацией ипратропия бромида и ксилометазолина. Препарат разрешен к применению с 18 лет, клинический эффект связан с уменьшением ринореи.

Интраназальные глюкокортикостероиды (ИНКС) имеют многолетний опыт клинического применения. Это высокоэффективные препараты, влияющие на раннюю и позднюю фазы аллергического воспаления, они уменьшают выраженность всех симптомов АР.

(B) 
Согласно рекомендации ARIA: «...ИНКС - наиболее эффективная фармакологическая терапия при AР...». «...Влияние топических стероидов на назальную блокаду и их противовоспалительные характеристики делают их предпочтительными...». ИНКС начинают действовать в течение первых суток. Максимальный эффект достигается на 3-5-е сутки лечения. В рекомендуемых дозах не оказывают системного действия. В $10 \%$ могут возникать побочные реакции в виде зуда, жжения, носовых кровотечений. Чаще побочные реакции не являются поводом для отмены, рекомендовано снизить дозу и правильно выполнять технику ингаляции. По данным исследований, длительность лечения ИКС может достигать до 36 месяцев. Лечение не сопровождается развитием атрофии.

Обладая высоким профилем безопасности, между собой ИНКС разделяются по риску нежелательных явлений, и если частота местных реакций примерно одинакова у всех препаратов (2-10\%), то системное действие их зависит от системной биодоступности.

Препараты беклометазона, будесонида имеют системную биодоступность до 46\%. Флютиказона пропионат, флютиказона фуроат, мометазона фуроат имеют значительно более низкую биодоступность (менее 5\%). В связи с низкой системной биодоступностью длительное лечение ИНКС является безопасным. Это обусловлено минимальной абсорбцией из желудочно-кишечного тракта и полной трансформацией в неактивные метаболиты при первом прохождении через печень. Исследования показали, что монотерапия ИКС более эффективна, чем терапия другими классами препаратов. ИНКС обладают синергизмом действия при сочетании с другими препаратами, например с АГП

АСИТ - высокоэффективный, модифицирующий болезнь метод лечения. Используется для лечения IgEопосредованных аллергических заболеваний, воздействует на все звенья аллергического процесса, модулирует Т- и В-клеточные ответы, ингибирует миграцию тучных клеток, базофилов и эозинофилов в ткани, воздействует на Т-регуляторные клетки, которые являются ключевыми регуляторами процессов периферической толерантности к аллергенам. При правильном использовании - это достаточно безопасный метод лечения. Появление сублингвальных форм значительно облегчило проведение терапии.

Аллергологическая служба СПб НИИ ЛОР имеет большой опыт работы с больными АР, т. к. именно в оториноларингологические учреждения чаще всего обращаются пациенты, имеющие проблемы с носовым дыханием. Ежегодно в СПб ЛОР НИИ консультируются, обследуются, лечатся примерно 880 пациентов с диагнозом АР. Большинство этих пациентов (89\%) имеют легкое и среднетяжелое течение АР, в то время как тяжелое течение имеют 11\% пациентов. Обратившиеся пациенты имеют главным образом обструктивный вариант течения АР (74\%). Наиболее часто у наших пациентов выявляется повышенная чувствительность к бытовым аллергенам (56\%), к пыльце - 18\% (это сенсибилизация как к пыльце деревьев, так и к пыльце луговых трав). Редко выявляется эпидермальная сенсибилизация - это около 5\%, смешанная сенсибилизация составляет $21 \%$.
У 48\% обратившихся диагноз АР поставлен впервые, у 7\% из этих пациентов длительность болезни составляет 20 лет и более, у 12\% - 10 лет и более. Эти цифры говорят о недостаточной диагностике аллергического ринита. Большинство пациентов длительное время лечились с диагнозом вазомоторного ринита и рецидивирующего острого синусита. Соответственно, эти пациенты не получали адекватной противовоспалительной терапии, не могли своевременно получить АСИТ.

Обращает внимание низкая эффективность предшествующей терапии, что нередко связано с недостаточной длительностью проводимых курсов фармакотерапии. Так, нередко длительность противовоспалительной терапии, в частности назначение ИНКС, составляла 2 недели, что является совершенно недостаточным для получения противовоспалительного эффекта и контроля над симптомами AР. Имеет смысл назначать ИНКС как минимум на 2 месяца.

Очень часто пациенты с АР длительно используют деконгестанты. По нашим данным, примерно у трети пациентов с АР имеет место в той или иной степени выраженный медикаментозный ринит. Около 4\% пациентов с медикаментозным ринитом используют деконгестанты практически ежедневно более 10 лет. Ведение таких больных имеет свои особенности.

АР примерно в 24\% случаев осложняется полипозным риносинуситом. Около 40\% пациентов с АР имеют БА. В свою очередь, около 90\% пациентов, обратившихся по поводу БА, имеют АР. В среднем интервал между дебютом БА и началом АР составляет от 3 до 12 лет. БА чаще всего носит легкий и среднетяжелый характер течения. Очень часто роль АР в этих случаях недооценивают, в то время как проведение терапии АР помогает более успешно контролировать БА. У 15\% пациентов, имеющих сочетание БА с АР, первым был поставлен диагноз БА, хотя, ретроспективно оценивая анамнез, симптомы АР были задолго до дебюта БА. Эта ситуация снижает эффективность лечения как АР, так и БА.

Хотелось бы представить два клинических случая диагностики и лечения АР из личной практики.

Пациентка Г., 1957 г. рождения, обратилась 09.10.2015 с жалобами на заложенность носа, чихание, кашель, зуд в носу, зуд глаз. Каждый симптом оценивался по 3-балльной шкале:

0 - жалоб нет, 1 - незначительные проявления, 2 - выраженные проявления, 3 - сильно выраженные проявления.

у данной пациентки интенсивность соответствовала 15 баллам.

Длительность заболевания более 20 лет, ранее аллергологом не консультирована, получала лечение у ЛОР-врача: периодически антибактериальную терапию и деконгестанты. Из сопутствующей патологии - хронический холецисто-панкреатит, жировой гепатоз. Артериальная гипертензия первой степени, умеренного риска, на фоне лечения имеет стабильное течение. Наследственность по аллергическим заболеваниям не отягощена. При сборе анамнеза были выявлены признаки бытовой сенсибилизации, которые были подтверждены прик-тестами. Выявлена повышенная чувствительность к клещам домашней пыли, папулы составили 10 мм (D. Pter.) и 12 мм (D. Far.). Было проведено спирометрическое исследование. Результат - без 
отклонений от нормы. Также были определены показатели оксида азота в выдыхаемом воздухе (FeNo) - общепринятый маркер эозинофильного воспаления и назальный оксид азота (NnO), значимость его как маркера эозинофильного воспаления обсуждается. FeNo составил 30,7 ррь (умеренное повышение, норма до 25 ppb), NnO составил 759 рpb (нормальный показатель, норма до 1000 ррb).

Был диагностирован хронический персистирующий аллергический ринит, средне-тяжелое течение, бытовая сенсибилизация.

Даны рекомендации по гипоаллергенному быту и назначена противовоспалительная терапия: флутиказона пропионат - 200 мкг/сут и Левоцетиризин - 5 мг/сут на один месяи.

Второй визит состоялся 25.11.2015 (через два месяца).

Пациентка отмечала свободное носовое дыхание, но ее беспокоили сухость, образование корочек в полости носа. Интенсивность симптомов аллергического ринита составила 5 баллов.

Посев из полости носа роста патогенной флоры не дал. Повторное спирометрическое исследование было в пределах нормы. Значение FeNo составило 32,36 ppb, NnO - 1347 ppb.

Несмотря на значимое повышение NnO было решено продолжить использовать флутиказона пропионат еще 2 месяца, но в дозе 100 мкг/сут и дополнительно увлажнять слизистую носа.

Третий визит состоялся 30.03.2016 (еще два месяца). Пациентка выполнила рекомендации, терапию перенесла хорошо, нежелательных явлений больше не отмечала. На момент осмотра жалоб не было. Спирометрическое исследование было в пределах нормы. Значение FeNO составило 13,38 ppb, NnO - 407,5 ppb. Интенсивность симптомов аллергического ринита составила 2 балла.

В данном примере обращает внимание поздняя диагностика АР. Кроме того, несмотря на нежелательные явления, была продолжена терапия флутиказона пропионатом. В процессе лечения отмечалось значимое снижение оксида азота в выдыхаемом воздухе - общепринятого маркера эозинофильного воспаления. Клиническая значимость назального оксида азота на сегодняшний момент обсуждается. На фоне длительного лечения ИНКС отмечалась явная положительная динамика: значимое уменьшение клинических проявлений и нормализация показателей оксида азота в выдыхаемом воздухе и назального оксида азота.

Пациент Д., 1996 г. рождения, более 5 лет страдает поллинозом, сенсибилизация к пыльще березы с довольно выраженными клиническими проявлениями. Получает второй курс АСИТ препаратом Фосталь. Первый курс АСИТ прошел гладко с хорошим клиническим эффектом. Cопутствующих заболеваний у данного пациента выявлено не было. Пациент пришел на рутинный визит 27.01.2016 года, т. к. получал АСИТ.

На визите отмечались жалобы на стойкую заложенность носа, ринорею. Выраженность симптомов соответствовала 6 баллам.

В середине декабря 2015 г. пациент перенес OP3 и самостоятельно использовал деконгестанты практиче- ски месяи. Ранее на фоне АСИТ жалоб на стойкий ринит пациент не предъявлял.

Были даны рекомендации об отмене деконгестантов и использовании флутиказона пропионата в дозе 200 мкг/сут как минимум 2 месяца.

Следующий визит состоялся 18.02.2016. Пачиент продолжал использовать деконгестанты, но флутиказона пропионат не использовал. Помимо жалоб на заложенность носа, появились жалобы на сердиебиение. Пациенту вновь были даны рекомендации об отмене деконгестантов и использовании флутиказона пропионата.

27.04.2016 состоялся следующий визит. Пациент смог отказаться от деконгестантов на фоне использования флутиказона пропионат в дозе 200 мкг/сут в течение двух месяцев. Жалоб на приеме не предъявлял. В настоящее время продолжает получать АСИТ с выраженным положительным эффектом.

В данном случае у пациента развился медикаментозный ринит на фоне длительного использования деконгестантов. В случае медикаментозных ринитов эффективно использование ИНКС длительными курсами (в среднем 2-4 месяца). Достаточно часто при проведении АСИТ требуется дополнительная медикаментозная терапия, в частности флутиказона пропионат, что позволило продолжить АСИТ, не меняя схему лечения и контролируя симптомы аллергического ринита.

В заключение хотелось бы еще раз подчеркнуть, что, несмотря на широту обсуждения и известность АР, сохраняется запоздалая диагностика этого заболевания и несвоевременно начатая и недостаточная терапия. Это ведет к развитию частых осложнений АР (синуситы, полипоз), развитию БА и, соответственно, повышенным экономическим затратам как со стороны пациентов, так и со стороны государства.

\section{ЛИТЕРАТУРА}

1. European Allergy White Paper, 1997, ARIA, 2001, 2008.

2. Аллергология и Иммунология. Национальное руководство. Краткое издание, под редакцией акад. РАН Р.М. Хаитова, проф. Н.И. Ильиной. с. 399. М.: « ГЭОТАР-Медиа» 2013. / Allergology and Immunology. National guidelines. Concise edition, edited by RAS Acad. RAS R.M. Khaitov, prof. N.I. Ilyina. p. 399. Moscow «GEOTAR-Media» 2013.

3. Scadding Get al. EAACI 2007. Abstract 1408.

4. Rally MC et al. Clin Drug Invest, 1996, 11: 278-88.

5. Tanner LA et al. Am J Manag Care, 1999, 5(suppl 4): S235-S247.

6. Juniper EF et al. J. Allergy Clin Immunol, 1994, 93: 413-23.

7. Ненашева Н.М. Бронхиальная астма и сопутствующие заболевания: в фокусе аллергический ринит. Практическая пульмонология, 2014, 1: 2-9. / Nenasheva N.M. Bronchial asthma and related diseases: focus on allergic rhinitis. Prakticheskaya Pulmonologiya, 2014, 1: 2-9. 8. de Croot EP et al. Thorax, 2012, 67(7): 582.

9. Ciprandi G, Caimmi D, Miraglia Del Giudice M, La Rosa M, Salpietro C, Marseglia GL. Recent developments in united airways disease. Allergy Asthma Immunol Res, 2012, 4(4): 171-177.

10. Eccles C. Anatomy and physiology of the nose and control of nasal airflow. In: Adkinson NF, Yunginger JW, Busse WW, et al, editors. Middleton's Allergy: Principles and Practice. 7th ed. Philadelphia: Elsevier, 2008: 701-711.

11. Дробик О.С., Насунова А.Ю. Аллергический ринит: взгляд аллерголога. Вестник отоларингологии, 2014, 2: 82-85. / Drobik O.S., Nasunova A.Y. Allergic rhinitis: an allergist's view. Vestnik Otolaringologii, 2014, 2: 82-85. 